\title{
Effect of interval training with non-invasive ventilation in severe chronic obstructive pulmonary disease-a prospective cohort study with matched control group
}

\author{
Monika Fekete ${ }^{1}$, Maria Kerti ${ }^{2}$, Vince Fazekas-Pongor ${ }^{1}$, Peter Balazs ${ }^{1}$, Zoltán Csizmadia ${ }^{2}$, \\ Anna N. Nemeth ${ }^{1}$, Stefano Tarantini ${ }^{3}$, Janos T. Varga ${ }^{2,4}$ \\ ${ }^{1}$ Department of Public Health, Semmelweis University, Faculty of Medicine, Budapest, Hungary; ${ }^{2}$ Koranyi Institute for Pulmonology, Budapest, \\ Hungary; ${ }^{3}$ Department of Biochemistry and Molecular Biology, University of Oklahoma Health Sciences Center, Oklahoma City, OK, USA; \\ ${ }^{4}$ Department of Pulmonology, Semmelweis University, Budapest, Hungary \\ Contributions: (I) Conception and design: JT Varga, M Kerti; (II) Administrative support: AN Nemeth, S Tarantini; (III) Provision of study materials \\ or patients: Z Csizmadia, M Fekete; (IV) Collection and assembly of data: M Kerti, JT Varga; (V) Data analysis and interpretation: V Fazekas- \\ Pongor, P Balazs; (VI) Manuscript writing: All authors; (VII) Final approval of manuscript: All authors. \\ Correspondence to: Janos T. Varga. Department of Pulmonology, Semmelweis University, Budapest, Hungary. Email: janosvargaster@gmail.com.
}

\begin{abstract}
Background In severe chronic obstructive pulmonary disease (COPD), interval training (IT) can be performed with oxygen support, which provides beneficial effect on metabolic processes, tissue perfusion, and peripheral muscle function.

Methods: A prospective cohort study with matched controls was performed on patients in Budapest at the Department of Pulmonary Rehabilitation of the National Koranyi Institute of Pulmonology between January 1, 2020 and March 1, 2020. After a complex condition assessment, both case and control patients participated in a 3-week long complex pulmonary rehabilitation (PR) program that included individual training, education, nutrition, and psychological counseling. Anthropometric and functional data of patients were recorded at both the beginning and end of the PR program. Our research aimed to assess the effect of non-invasive ventilation (NIV) in patients with severe COPD who underwent IT.
\end{abstract}

Results: A total of 18 [male/female: $10(55.6 \%) / 8(44.4 \%)$ ] patients were enrolled in our study. IT with NIV significantly improved the patients' 6-minute walking distance (6MWD) (m) [216.0 (211.5-233.7) vs. 274.0 (247.5-313.5); $\mathrm{P}<0.001]$ and quality of life [COPD Assessment Test (CAT): 29.0 (26.9-32.0) vs. 15.0 (13.5-17.5); $\mathrm{P}<0.001$ ], [modified Medical Research Council (mMRC): 2.0 (1.5-2.0) vs. 1.0 (1.0-2.0); $\mathrm{P}=0.009]$; in addition, there was a significant increase in inspiratory vital capacity (IVC) (ref\%) [65.0 (63.069.0) vs. 74.7 (70.5-75.0); $\mathrm{P}=0.015]$, in chest kinematics (cm) [3.0 (2.5-4.0) vs. 5.5 (4.0-6.5); $\mathrm{P}<0.001]$, work rate (Watt) [25.0 (24.0-27.0) vs. 36.0 (35.0-38.0); $\mathrm{P}<0.001]$, volume of oxygen consumption $\left[\mathrm{VO}_{2} / \mathrm{kg}(\mathrm{mL} /\right.$ kg/min): 8.8 (8.5-9.2) vs. 10.3 (10.2-10.7); $\mathrm{P}<0.001]$, and Body-mass index, airflow Obstruction, Dyspnea, and Exercise (BODE) index [5.0 (5.0-6.7) vs. 4.0 (3.0-5.0); $\mathrm{P}=0.006]$, while the results of the control group were non-significant [6MWD, maximal inspiratory pressure (MIP), CAT, mMRC, BODE index].

Conclusions: In severe COPD, IT with NIV is well tolerated during PR, it has a significant beneficial effect on the quality of life, improves exercise capacity and respiratory functions, decreases dynamic hyperinflation and dyspnea.

Keywords: Chronic obstructive pulmonary disease (COPD); pulmonary rehabilitation (PR); interval training (IT); biphasic airway pressure (BIPAP); non-invasive ventilation (NIV); quality of life

Submitted Feb 13, 2021. Accepted for publication Mar 26, 2021.

doi: $10.21037 / \mathrm{apm}-21-378$

View this article at: http://dx.doi.org/10.21037/apm-21-378

(c) Annals of Palliative Medicine. All rights reserved. 


\section{Introduction}

Chronic obstructive pulmonary disease (COPD) is a preventable and treatable population-wide disease characterized by persistent, and generally progressive, bronchial obstruction (1). Increased airway flow resistance of the lungs is a consequence of inhalation tissuedamaging gases and particles, which is most obvious in the pathologically increased inflammatory response to tobacco smoking (2). Poor exercise capacity is one of the main symptoms of COPD (3), which significantly impairs the patients' quality of life. This is largely due to dynamic pulmonary hyperinflation (DH) caused by respiratory dysfunction (4). Due to dynamic hyperinflation-which correlates with the degree of obstruction and the Global Initiative for Chronic Obstructive Lung Disease (GOLD) stage of the disease-the respiratory mechanics, chest kinematics, and the normal pathway of the diaphragm are altered (5), and they result in end-expiratory lung volume, residual volume increase (6), narrowed ventilation, and increased dyspnea (7-9).

Pulmonary rehabilitation (PR) is the standard treatment for COPD, which increases physical activity more than any other form of therapy (10). Duration of the inpatient respiratory rehabilitation program is approximately three weeks. A wide range of procedures is available to improve respiratory dysfunction and respiratory mechanics, which reduce chest hyperinflation, increase respiratory endurance, and improve bone-articular rib basket movements (5-10). The physiological benefit is primarily determined by the intensity of training during rehabilitation (11); however, the vast majority of people with severe COPD, partly due to muscle weakness and limited ventilation, tolerated poorly the high intensity training (12). Endurance training - in its continuous and interval forms-improves tissue blood supply and perfusion, have a beneficial effect on peripheral muscle function (13), and can be performed in severe COPD with oxygen support, because it has a beneficial effect on metabolic processes (14). During interval training (IT), one minute of cycling (on a gym bike) is followed by one minute of rest $2-3$ times a day for 15-20 minutes in individualised form supervised by a physiotherapist. Intensity of the training can be monitored by oxygen saturation and heart rate measurements at the beginning and end of the training (15). IT has been shown to improve patients' cardiovascular status, and its application is as effective as continuous training, providing equivalent physiological training effects (10). However, it is important to emphasize that in severe COPD exercise regimes should be performed with oxygen support, if necessary (16). Non-invasive ventilation (NIV) is a form of positive pressure ventilation without endotracheal tube, by using non-invasive devices (e.g., nasal mask, face mask). The concept of two-phase positive airway pressure ventilation [biphasic airway pressure (BIPAP)] means that breathing cycles take place between two different continuous pressure levels, thus provide a kind of controlled ventilation; however, the patient's spontaneous breathing initiatives are accepted at both pressure levels, and can be assisted with additional pressure support (17). The effect of non-invasive mechanical respiration support has been extensively studied in acute COPD exacerbations (see randomized controlled trials), and it was demonstrated that non-invasive mechanical ventilation significantly reduced respiratory acidosis, respiratory rate, dyspnea, duration of hospitalization, and mortality, improved quality of life, and avoided intubation (Evidence A) (18-21).

IT in severe COPD indicated a more favorable effect in physiological variables over continuous training-improving exercise capacity, reducing dyspnea-and better outcomes were observed with NIV, despite the theoretical value of NIV during training, there is little high-quality evidence to support its use. The combination of home NIV and exercise has been shown to improve blood gases and 6-minute walking distance $(6 \mathrm{MWD})$ to a greater extent than either intervention alone, and when performed in complex PR, the effects were even more significant $(22,23)$. The aim of our present study was to examine whether patients' exercise capacity, respiratory function, thoracic bypass, quality of life, and dynamic hyperinflation (inferred from inspiratory capacity) could be reduced by IT with NIV in severe COPD.

We present the following article in accordance with the Strengthening the Reporting of Observational Studies in Epidemiology (STROBE) reporting checklist (available at http://dx.doi.org/10.21037/apm-21-378).

\section{Methods}

\section{Study design and target population}

We performed a prospective cohort study with matched control group involving COPD patients at the National Koranyi Institute for Pulmonology between January 1, 2020 and March 1,2020 . Inclusion criteria were age ( $\geq 40$ years) and concurrent diagnosis of COPD [post-bronchodilation forced expiratory volume in the first second/forced vital 
capacity $\left(\mathrm{FEV}_{1} / \mathrm{FVC}\right)<70 \%$ ] (24), patients with severe, but stable COPD were admitted to the PR ward, degree of obstruction ranged from severe $\left(\mathrm{FEV}_{1}: 30-50 \%\right)$ to very severe $\left(\mathrm{FEV}_{1}<30 \%\right)$ based on the percentage of $\mathrm{FEV}_{1}$. Exclusion criteria were acute exacerbation, severely symptomatic heart disease, chronic oxygen therapy (resting oxygen saturation less than 89 percent), and orthopedic or joint disease limiting exercise capacity. The members of the control group were also selected (computer-generated list) from the patients at the Department of Pulmonary Rehabilitation, National Koranyi Institute of Pulmonology, Budapest, Hungary from the available database (89 patients; between January 1, 2020 and March 1, 2020) and matched the case group by age, gender, body mass index (BMI), respiratory function, admission diagnosis, and comorbidities. All our patients were given oral and written information on the study, and they signed a statement of informed consent. The participation was voluntary. The study protocol was approved by the Ethical Committee of the National Koranyi Institute for Pulmonology with the registration number 25/2017 and it complies with the Helsinki Declaration (as revised in 2013). The study was registered with ISRCTN13019180 registration number at the ISRCTN registry. Patients were given oral and written information prior to the assessment, and then they signed a statement of consent.

\section{Complex PR}

After a complex physiological assessment in the hospital's PR ward, both case and control patients participated in a 3-week long complex PR program that included individual training (case group with oxygen support), education, nutrition, and psychological counseling. The complex PR took place under the guidance of a pulmonologist, and in addition, physiotherapists, psychologists, dietitians and respiratory nurses were also involved in the complex program. Measurements were performed in the case and control group by a physiotherapist under specialist supervision before and after rehabilitation. When designing the study, we wanted to achieve a larger number of exposed patients, however, we had to stop the research due to the coronavirus epidemic. The workout included a 30-minute group exercise session (controlled breathing technique, chest mobility-enhancing and muscle-strengthening exercises) 2-3 times a day and individual training (on a gym bike and treadmill and with an arm ergometer), comorbidities and current condition were taken into account. Training was followed in both groups by detailed patient education, which included teaching optimal drug treatment, dietary counseling, and mastering and maintaining adaptive behavioral and lifestyle patterns. Different anthropometric and functional data of the patients were recorded both at the beginning and at the end of the complex PR program (respiratory function parameters, physical performance, and quality of life). The program was considered successful if patients completed at least 75 percent of the sessions.

\section{Assessment of physiological parameters and measurements}

\section{IT}

The individual IT sessions were done on a gym bike in a dynamic form, under physiotherapist's supervision. The training was performed with oxygen support, to positively support metabolic processes, while the control group trained without oxygen support. At the beginning and at the end of the training, its intensity was monitored by oxygen saturation and heart rate measurement. Our goal was to increase the workload as much as possible, thus consulting physicians, we increased the time of training, workload, or both.

\section{Examination of respiratory function}

All patients underwent a baseline respiratory function test according to American Thoracic Society/European Respiratory Society (ATS/ERS) standard criteria, followed by a post-bronchodilation test (Vmax 229 and Autobox 6200, Sensormedics, Yorba Linda, CA, USA). Bronchodilation was achieved by inhalation of 400 micrograms salbutamol (Ventolin), in accordance with international recommendations (25). Dynamic lung volumes were defined as the amount of air expelled in the first second $\left[\mathrm{FEV}_{1}(\mathrm{ref} \%)\right]$, vital capacity [FVC (ref\%)], the degree of airway obstruction $\left(\mathrm{FEV}_{1} / \mathrm{FVC}\right)$, inspiratory capacity in liters and percent [IVC (L), IVC (ref\%)], with GLI-defined (Global Lung Function Initiative) normal spirometry (z-score) (26).

\section{Cardio-pulmonary exercise test}

Before exercise, the patients underwent a brief physical examination, measurement of vital parameters (pulse, blood pressure, respiratory rate, pulse oximetry, body weight and height) and respiratory function test. An electrically braked bicycle ergometer (Ergoline-900, Marquette) was set to produce a continuously increased power load. The work rate (WR) was chosen not to exceed the submaximal heart rate. Alternatively, if a spiroergometric examination was performed in advance, we aimed at 80 percent of 
the maximum power achieved. Without a preliminary spiroergometric test, the submaximal heart rate was determined as follows: $(220-$ age $) \times 0.6-0.8 / \mathrm{min}$. During the six-minute walk test (6MWT), patients were asked to walk down the aisle for 6 minutes and the maximum walking distance was recorded (27).

\section{Initial setting of bi-level positive airway pressure (BIPAP) parameters}

The NIV was performed during interval loading through a face mask in a pressure-controlled mode with the following parameters: $\mathrm{FiO}_{2}$ (fraction of inspired oxygen): $100 \%$; IPAP (inspiratory positive airway pressure): $12 \mathrm{H}_{2} \mathrm{Ocm}$; EPAP (expiratory positive airway pressure): $8 \mathrm{H}_{2} \mathrm{Ocm}$; trigger: $2 \mathrm{~L} / \mathrm{min}$; PS (pressure support): $8 \mathrm{H}_{2} \mathrm{Ocm}$; Tinsp (inspiratory time): $0.8 \mathrm{~s}$.

\section{Quality of life examination}

We used the COPD Assessment Test (CAT) as a quality of life measurement. The patients responded to eight questions, scoring the symptoms from 0 to 5 , where 0 indicates healthy condition, while 5 points indicate severe symptoms. Cough, the amount of sputum, hyperinflation, the load-bearing capacity when climbing stairs, and the level of energy were evaluated subjectively, as well as whether the patients dare to leave home, or whether their illness affects their sleep (28). The mMRC (modified Medical Research Council) questionnaire evaluates the dyspnea response to different load levels. The degree of dyspnoea was evaluated provoked by different workload in 5 points (29).

\section{Examination of chest deviation}

Chest circumference was measured at the level of processus xiphoideus by a centimeter tape at the end of exhalation and then at the end of inhalation. The difference between these circumferences indicates the value of chest deviation. Exhalation-inhalation was repeated three times to determine more accurately the chest kinematics (30).

\section{Maximal inspiratory pressure (MIP)}

MIP refers to the function of the diaphragm. It is measured by a digital device, Power Breathe Kh1 (POWER breathe International Limited, Southam, UK). Values are given in $\mathrm{cmH}_{2} \mathrm{O}$ and a scale shows a textual evaluation of the strength.

\section{Hand grip strength (HGS)}

It is measured by the Kern dynamometer (2016 KERN \& SOHN GmbH Ziegelei 172336 Balingen, Germany) and its value is given in $\mathrm{kg}(31)$.

Body-mass index, airflow Obstruction, Dyspnea, and Exercise (BODE) index

According to the international standard, the severity of COPD is assessed by considering four factors: $\mathrm{B}, \mathrm{BMI}$; $\mathrm{O}$, obstruction $\left[\mathrm{FEV}_{1}(\mathrm{ref} \%)\right]$; D, dyspnea (mMRC); E, exercise (6MWD). The higher the score, the more severe the disease, with a maximum score of 10 (32).

\section{Statistical analysis}

Continuous variable data were presented in median (interquartile range) form, categorical variables in absolute values. The Shapiro-Wilk test was used to check normality. Because our data did not follow a normal distribution, the comparative analysis between groups was performed by the Mann-Whitney U-test. A 95\% confidence interval was considered for all statistical tests, and the significance limit used was $\mathrm{P}<0.05$. Statistical calculations were performed with STATA SE-10.0 (StataCorp, College Station, TX).

\section{Results}

The efficacy of complex PR and the differences between the two groups (case and control groups) were examined separately. The IT group with NIV consisted of 18 patients with COPD [male/female: 10/8; $\mathrm{FEV}_{1}$ (ref\%): 32.0 (25.0-39.5); median age (years): 65.0 (61.5-68.5); BMI $\left.\left(\mathrm{kg} / \mathrm{m}^{2}\right): 22.6(19.2-25.4)\right]$. The control group also included 18 patients with COPD [male/female: $10 / 8, \mathrm{FEV}_{1}(\mathrm{ref} \%)$ : 24.0 (20.5-26.7), median age: $64.5(60.2-67.7)$ years, BMI: 21.1 (19.9-23.9)]. Demographic and functional characteristics of patients in median and interquartile range are shown in Table 1.

Specific functional parameters were recorded on the status sheet at the beginning and the end of our PR program. As its result, we observed significant positive changes in chest kinematics, exercise tolerance, respiratory function values, respiratory mechanical parameters, and the program improved significantly functional parameters in the group of COPD patients undergoing IT with NIV (see Tables 2,3). As a result of the rehabilitation program, the patients' load capacity also improved significantly (6MWD) the respiratory muscle (IVC), like the peripheral muscle function due to the favorable effect on metabolism thanks to the IT with NIV. We observed significantly increased chest kinematic, work rate, and volume of oxygen 
Table 1 Demographic and functional characteristics of the COPD patients

\begin{tabular}{lccc}
\hline Variables & Cases $(\mathrm{n}=18)$ & Controls $(\mathrm{n}=18)$ & $\mathrm{P}$ value \\
\hline Mean age (years) (IQR) & $65.0(61.5-68.5)$ & $64.5(60.2-67.7)$ & 0.280 \\
Male/female (n, \%) & $10(55.6) / 8(44.4)$ & $10(55.6) / 8(44.4)$ & - \\
BMI (kg/m²) & $22.6(19.2-25.4)$ & $21.1(19.9-23.9)$ & 0.309 \\
FEV $($ ref\%) & $32.0(25.0-39.5)$ & $24.0(20.5-26.7)$ & 0.001 \\
FVC (ref\%) & $63.0(61.5-64.0)$ & $53.5(49.2-62.0)$ & 0.042 \\
IVC (ref\%) & $65.0(63.0-69.0)$ & $53.0(49.0-57.7)$ & 0.001
\end{tabular}

Data are presented as median (interquartile range) or as frequency and percentage. $\mathrm{P}<0.05$ means the two indicators were significantly correlated. COPD, chronic obstructive pulmonary disease; BMI, body mass index; FEV ${ }_{1}$, forced expiratory volume in post-bronchodilator one second; FVC, forced vital capacity; IVC, inspiratory vital capacity.

Table 2 Functional characteristics of the non-invasive ventilated and control COPD patients before and after rehabilitation

\begin{tabular}{|c|c|c|c|c|c|c|}
\hline $\begin{array}{l}\text { Functional } \\
\text { parameters }\end{array}$ & \multicolumn{3}{|c|}{ Cases $(n=18)$} & \multicolumn{3}{|c|}{ Controls $(n=18)$} \\
\hline 6MWD (m) (IQR) & $216.0(211.5-233.7)$ & $274.0(247.5-313.5)$ & $<0.001$ & $333.5(141.0-378.0)$ & $345.0(303.0-433.5)$ & 0.194 \\
\hline FVC (ref\%) & $63.0(61.5-64.1)$ & $73.0(70.0-76.0)$ & 0.012 & 53.5 (49.3-62.0) & $60.0(44.5-65.0)$ & 0.966 \\
\hline IVC (ref\%) & $65.0(63.0-69.0)$ & 74.7 (70.5-75.0) & 0.015 & $53.0(49.0-57.7)$ & $58.5(50.0-66.7)$ & 0.159 \\
\hline WR (Watt) & $25.0(24.0-27.0)$ & $36.0(35.0-38.0)$ & $<0.001$ & $23.1(22.0-25.4)$ & $29.4(27.5-32.1)$ & $<0.001$ \\
\hline $\mathrm{VO}_{2} / \mathrm{mL} / \mathrm{kg} / \mathrm{min}$ & $8.8(8.5-9.2)$ & $10.3(10.2-10.7)$ & $<0.001$ & $7.3(6.8-8.3)$ & $8.8(7.9-9.6)$ & 0.029 \\
\hline $\operatorname{MIP}\left(\mathrm{cmH}_{2} \mathrm{O}\right)$ & $74.0(60.5-77.2)$ & $76.0(70.5-84.2)$ & 0.687 & 44.5 (36.7-69.7) & $46.0(38.2-70.5)$ & 0.539 \\
\hline HGS (kg) & $22.2(19.7-33.1)$ & $25.1(19.6-32.1)$ & 0.825 & $27.0(18.2-31.4)$ & $27.4(22.4-35.7)$ & 0.335 \\
\hline CAT & $29.0(26.9-32.0)$ & $15.0(13.5-17.5)$ & $<0.001$ & $20.5(18.0-25.8)$ & $16.0(12.3-18.0)$ & 0.077 \\
\hline
\end{tabular}

Data are presented as median (interquartile range). $\mathrm{P}<0.05$ means the two indicators were significantly correlated. COPD, chronic obstructive pulmonary disease; 6MWD, six-minute walking distance; FVC, forced vital capacity; IVC, inspiratory vital capacity; CK, chest kinematic; WR, work rate; $\mathrm{VO}_{2}$, volume for oxygen consumption; MIP, maximal inspiratory pressure; HGS, hand grip strength; BODE, Body mass index, airflow Obstruction, Dyspnoea, Exercise capacity; mMRC, modified Medical Research Council Dyspnoea Scale; CAT, COPD Assessment Test.

consumption. As a result of the program, the patients' quality of life (CAT: 29.0 vs. 15.0; $\mathrm{P}<0.001)$ and the score of the dyspnea scale significantly improved (mMRC: 2.0 vs.1.0; $\mathrm{P}=0.009$ ). In addition, there was a significant decrease in dynamic hyperinflation which reduced workload, and improvement in quality of life as suggested by an increase of inspiratory vital capacity. As the load capacity increased, the severity of the disease decreased significantly (BODE-index) see Table 3.

Specific functional parameters of the control COPD group are shown in Table 2. The PR program improved patient workload (6MWD) and respiratory muscle (IVC) and improved quality of life (CAT), but the difference was not significant (see Tables 2,3). Only chest kinematic (3.5 vs. $4.7 ; \mathrm{P}=0.008)$; and work rate $(23.1$ vs. $29.4 ; \mathrm{P}<0.001)$ improved significantly.

\section{Discussion}

In the present study, we examined 18 cases and 18 matched 
Table 3 Changes in BODE index among non-invasive ventilated and control COPD patients before and after rehabilitation

\begin{tabular}{|c|c|c|c|c|c|c|c|c|c|c|c|c|}
\hline & \multicolumn{10}{|c|}{ BODE index } & \multirow{2}{*}{ Change } & \multirow{2}{*}{$P$ value } \\
\hline & 0 & 1 & 2 & 3 & Total & 0 & 1 & 2 & 3 & Total & & \\
\hline \multicolumn{13}{|c|}{ Changes in BODE index among non-invasive ventilated COPD patients } \\
\hline $\mathrm{FEV}_{1}(\mathrm{ref} \%)(\mathrm{n})$ & 0 & 3 & 3 & 12 & 45 & 0 & 3 & 6 & 9 & 42 & -3 & 0.524 \\
\hline $\operatorname{mMRC}(\mathrm{n})$ & 6 & 10 & 2 & 0 & 14 & 12 & 5 & 1 & 0 & 7 & -7 & 0.071 \\
\hline BMI $\left(\mathrm{kg} / \mathrm{m}^{2}\right)(\mathrm{n})$ & 12 & 6 & 0 & 0 & 6 & 14 & 4 & 0 & 0 & 4 & -2 & 0.471 \\
\hline Total & & & & & 98 & & & & & 73 & -25 & 0.006 \\
\hline \multicolumn{13}{|c|}{ Changes in BODE index among control COPD patients } \\
\hline $\operatorname{mMRC}(\mathrm{n})$ & 1 & 10 & 6 & 1 & 25 & 4 & 10 & 4 & 0 & 18 & -7 & 0.100 \\
\hline $\operatorname{BMI}\left(\mathrm{kg} / \mathrm{m}^{2}\right)(\mathrm{n})$ & 9 & 9 & 0 & 0 & 9 & 10 & 8 & 0 & 0 & 8 & -1 & 0.747 \\
\hline Total & & & & & 104 & & & & & 91 & -13 & 0.118 \\
\hline
\end{tabular}

$\mathrm{P}<0.05$ means the two indicators were significantly correlated. BODE, Body mass index, airflow Obstruction, Dyspnoea, Exercise capacity; COPD, chronic obstructive pulmonary disease; $\mathrm{FEV}_{1}$, post-bronchodilator forced expiratory volume in one second; 6MWD, six-minute walking distance; mMRC, modified Medical Research Council Dyspnoea Scale; BMI, body mass index.

control patients with stable, severe COPD, and found that complex PR and IT with NIV significantly improved the patients' load capacity, quality of life, chest kinematics, and peripheral muscle function compared to the control group patients. Our study is the first to demonstrate a significant performance-enhancing effect of non-invasive oxygen supplementation during training with severe COPD patients. Patients participated in the two groups in a complex PR program containing the same components except for IT with NIV. Patients in the two groups responded differently to the complex program. In the IT group with NIV, there was a significant improvement in functional parameters, a positive effect on workload, muscle metabolism, quality of life, while there was no significant improvement in the matched control group. The complex PR has reduced the rate of dynamic hyperinflation, which is important, because dynamic hyperinflation severely limits patients' quality of life and workload respectively $(33,34)$.

The effectiveness of complex PR is supported by the highest level of evidence $(35,36)$. Evidence-based, randomized, controlled trials have shown improved performance and quality of life in patients with COPD $(12,37)$, regardless of the severity of their condition. The beneficial respiratory, circulatory, and metabolic effects of IT are also well known (38). Compared to continuous training, IT leads to less DH, it allows a significantly longer tolerable training period, and it results in a lower degree of exercise dyspnea (38). Decreased exercise capacity is a major factor in the isolation of patients with severe COPD in particular, and low physical activity also helps to induce subsequent exacerbation (39). It is important to determine the appropriate intensity, and slowly increase the load in order to achieve the best cardiopulmonary and performance-enhancing effect (11). In addition, it is important to educate and motivate patients, to set realistic goals for a more active and health-oriented lifestyle in the long run, as physical activity in everyday life is also crucial for their prognosis (40).

In case of acute COPD exacerbation, NIV can be used very safely (41). In patients with acute exacerbating COPD, NIV leads to a rapid improvement of blood gas parameters. The main result is an early and permanent decrease of $\mathrm{PaCO}_{2}$ levels and a consequent increase in $\mathrm{pH}$-values. It also reduces the need for endotracheal intubation (42). Numerous studies have shown that patients undergoing regular endurance training are less likely to be hospitalized 
for acute exacerbation, and even if they require in-patient care, their symptoms are milder and the number of days spent in hospital is lower compared to non-trainees (43-45). It is well known that not all the patients with COPD are able to perform intense workouts due to dyspnea, fatigue, and rapid exhaustion, and they rather tolerate IT better than continuous exertion (46). The benefits of non-invasive respiratory support during IT are: sustained spontaneous respiration, better oxygen supply, higher cardiac output, better tissue perfusion, and better peripheral muscle function, which result in a significant increase in performance (47).

Dynamic hyperinflation often develops in COPD. This has a great clinical significance because it contributes to dyspnea, reduces exercise tolerance, and increases the incidence of comorbidities (48). Due to the detrimental effect of inflammatory mediators in the small airways, the so-called remodeling (transformation) and tissue destruction occur in the lung parenchyma (49). Dynamic hyperinflation strains heavily the cardiovascular system, as an increasing number of studies demonstrated that $\mathrm{DH}$, which is further exacerbated by strain, increased the use of cardiopulmonary system reserves, especially in the advanced stages $(33,50)$. The function of the diaphragm in COPD as a primary inspiratory muscle is also very important (51). In our present study, the MIP increased due to the PR since it tuned the breathing towards more economical pattern.

The study of Menadue et al. found that in patients with severe or very severe COPD, non-invasive positivepressure ventilation improved peak performance (17 percent improvement) and endurance training (59 percent improvement) in the complex PR program, and training intensity also increased by 13 percent (52). In our research, we found a significant improvement in dyspnea scale (mMRC) and quality of life (CAT) during IT with NIV, and our results are consistent with those of Hui et al. (53), Paz-Díaz et al. (54) and Spencer et al. (55). Joyner et al. put forward that regular endurance training leads to an adaptation of skeletal muscle that prevents an increase in lactate levels, i.e., in the presence of oxygen, the body is able to break down the lactate produced during the exercise. This requires a relatively low intensity (56). This process is mediated by the activation of peroxisome proliferator-activated receptor gamma coactivator 1-alpha (PGC-1 $\alpha$ ), which changed the composition of the LDH (lactate dehydrogenase) complex isoenzyme and decreased the activity of the lactate-producing LDH-A enzyme while increasing the activity of the LDH-B lactate metabolizing enzyme (57). Through physical activity, PGC-
$1 \alpha$ also has an effect on vascularization, ROS (reactive oxygen species) detoxification, and reduces inflammation. PGC- $1 \alpha$ also affects mitochondrial and metabolic genes, load genes (e.g., MyoD, p21), and neuromuscular junction genes. Overall, physical activity has beneficial effects on metabolic processes, cardiovascular status, and muscle status as well (56-58).

In COPD patients, a wide range of training programs is available as an integral part of $\mathrm{PR}$-lower and upper limb trainings, strength and endurance respiratory muscle trainings, whole body vibration training - which in some cases can be supplemented with individual complementary therapy, chest physiotherapy or fascia relaxing techniques. The PR program is complex, carefully designed, and it takes into account the patients' individual needs as well as their comorbidities. The treatment plan is established by the physiotherapist in close cooperation with the respiratory rehabilitation specialist based on the results of functional condition assessment and the opinion of the cardiologist. Group exercise also has a positive effect on mental health, thus all patients should be encouraged to participate in these sessions and perform tasks according to their individual condition.

We acknowledge that our present research has certain limitations to be mentioned. A relatively smaller sample size and single-center patient modality was present, but it was a physiological study. Although patients in the control group had significantly weaker lung function and the result of the complex PR program was not or hardly significant for them, the effect of IT with NIV on physiological parameters was clearly visible and highly convincing in the case group. Another disadvantage of our study was that our research could not meet the blindness criterion, i.e., the case group members were aware of the purpose of the study, as they received oxygen through a full face mask during IT and their results were objectively measured before and after complex PR. However, it was an advantage in our study that all patients selected for the study successfully completed complex rehabilitation program, there was no dropout. We performed a prospective cohort study with matched control group, most of the physiological studies, therefore biases cannot be completely ruled out. Nevertheless, it was the first study in Hungary involving patients with severe but stable COPD who benefited from non-invasive positive pressure ventilation using a full face mask-instead of a nose mask-with no leakage. The results of our research showed that the values of IVC (ref\%), CK, 6MWD, MIP, CAT, and $\mathrm{mMRC}$ were significantly improved, i.e., IT with NIV 
during complex PR can be a safe and effective advantage in the therapy.

\section{Conclusions}

The complex PR, one of the standard treatment tools for COPD, is a multidimensional, non-pharmacological intervention that has been demonstrated to reduce dyspnea, increase patient performance, and improve quality of life. Overall, elements of the PR program also improved the function of respiratory muscles and peripheral muscles by a beneficial effect on metabolism. Having examined 18 patients with severe but stable COPD, we found that IT with NIV in severe COPD significantly improved patients' exercise capacity, quality of life, chest kinematics, and peripheral muscle function, while the results of the matched control group proved not to be significant [IVC (ref\%), 6MWD, MIP, CAT, mMRC]. We also found a significant improvement in inspiratory muscle function and chest deviation in noninvasive-ventilation group, as well as a significant decrease in dynamic hyperinflation, as suggested by an increase in inspiratory capacity.

\section{Acknowledgments}

Funding: None.

\section{Footnote}

Reporting Checklist: The authors have completed the STROBE reporting checklist. Available at http://dx.doi. org/10.21037/apm-21-378

Data Sharing Statement: Available at http://dx.doi. org/10.21037/apm-21-378

Peer Review File: Available at http://dx.doi.org/10.21037/ apm-21-378

Conflicts of Interest: All authors have completed the ICMJE uniform disclosure form (available at http://dx.doi. org/10.21037/apm-21-378). The authors have no conflicts of interest to declare.

Ethical Statement: The authors are accountable for all aspects of the work in ensuring that questions related to the accuracy or integrity of any part of the work are appropriately investigated and resolved. The study protocol was approved by the Ethical Committee of the National Koranyi Institute for Pulmonology with the registration number 25/2017 and it complies with the Helsinki Declaration (as revised in 2013). The study was registered with ISRCTN13019180 registration number at the ISRCTN registry. Patients were given oral and written information prior to the assessment, and then they signed a statement of consent.

Open Access Statement: This is an Open Access article distributed in accordance with the Creative Commons Attribution-NonCommercial-NoDerivs 4.0 International License (CC BY-NC-ND 4.0), which permits the noncommercial replication and distribution of the article with the strict proviso that no changes or edits are made and the original work is properly cited (including links to both the formal publication through the relevant DOI and the license). See: https://creativecommons.org/licenses/by-nc-nd/4.0/.

\section{References}

1. Böszörményi Nagy Gy, Balikó Z, Kovács G, et al. Guideline for the diagnosis and treatment of chronic obstructive pulmonary disease (COPD) in primary care, specialist- and emergency care. Med Thor 2014;67:76112.

2. Fekete M, Fazekas-Pongor V, Szöllősi G, et al. Metabolic consequences of chronic obstructive pulmonary disease. Orv Hetil 2021;162:185-91.

3. Fekete M, Pákó J, Szöllősi G, et al. Significance of nutritional status in chronic obstructive pulmonary disease: a survey. Orv Hetil 2020;161:1711-9.

4. Varga J. Chronic obstructive pulmonary disease. Háziorv Továbbk Szle 2018;23:26-30.

5. Varga J, Casaburi R, Ma S, et al. Relation of concavity in the expiratory flow-volume loop to dynamic hyperinflation during exercise in COPD. Respir Physiol Neurobiol 2016;234:79-84.

6. Gagnon P, Guenette JA, Langer D, et al. Pathogenesis of hyperinflation in chronic obstructive pulmonary disease. Int J Chron Obstruct Pulmon Dis 2014;9:187-201.

7. O'Donnell DE, Elbehairy AF, Webb KA, et al. Canadian Respiratory Research Network The link between reduced inspiratory capacity and exercise intolerance in chronic obstructive pulmonary disease. Ann Am Thorac Soc 2017;14:S30-S39.

8. Ma S, Hecht A, Varga J, et al. Breath-by-breath assessment of progressive airflow limitation during exercise in COPD: a new method. Respir. Med 2010;104:389-96. 
9. Mahler DA, O'Donnell DE. Recent advances in dyspnea. Chest 2015;147:232-41.

10. Varga J, Porszasz J, Boda K. Supervised high intensity continuous and interval training vs. self-paced training in COPD. Respir Med 2007;101:2297-304.

11. Casaburi R, Patessio A, Ioli F, et al. Reductions in exercise lactic acidosis and ventilation as a result of exercise training in patients with obstructive lung disease. Am Rev Respir Dis 1991;143:9-18.

12. McCarthy B, Casey D, Devane D, et al. Pulmonary rehabilitation for chronic obstructive pulmonary disease. Cochrane Database Syst Rev 2015;(2):CD003793.

13. Gloeckl R, Schneeberger T, Jarosch I, et al. Pulmonary Rehabilitation and Exercise Training in Chronic Obstructive Pulmonary Disease. Dtsch Arztebl Int 2018;115:117-23.

14. Ergan B, Oczkowski S, Rochwerg B, et al. European Respiratory Society guidelines on long-term home noninvasive ventilation for management of COPD. Eur Respir J 2019;54:1901003.

15. Kerti M, Balogh ZS, Halasz A, et al. COPD assessment for symptoms and functional condition in pulmonary rehabilitation. ERS Annual Congress Amsterdam: P2218. 2016.

16. Varga J. Practical and theoretical principles of pulmonary rehabilitation. Levels of treatment. Korányi Bulletin 2016;1:44-7.

17. Chawla R, Dixit SB, Zirpe KG, et al. ISCCM Guidelines for the Use of Non-invasive Ventilation in Acute Respiratory Failure in Adult ICUs. Indian J Crit Care Med 2020;24:S61-S81.

18. Shah NM, D'Cruz RF, Murphy PB. Update: non-invasive ventilation in chronic obstructive pulmonary disease. J Thorac Dis 2018;10:S71-S79.

19. Kerti M, Balogh ZS, Varga J. New measures of physiotherapy in pulmonology. Med Thor 2015;68:200-5.

20. Osadnik CR, Tee VS, Carson-Chahhoud KV, et al. Non-invasive ventilation for the management of acute hypercapnic respiratory failure due to exacerbation of chronic obstructive pulmonary disease. Cochrane Database Syst Rev 2017;7:CD004104.

21. Varga J, Boda K, Somfay A. Controlled and at-home (noncontrolled) dynamic training in rehabilitation of COPD patients. Orv Hetil 2005;146:2249-55.

22. Salturk C, Karakurt Z, Takir HB, et al. Comparison of exercise capacity in COPD and other etiologies of chronic respiratory failure requiring non-invasive mechanical ventilation at home: retrospective analysis of 1-year follow- up. Int J Chron Obstruct Pulmon Dis 2015;10:2559-69.

23. Duiverman ML, Wempe JB, Bladder G, et al. Two-year home-based nocturnal noninvasive ventilation added to rehabilitation in chronic obstructive pulmonary disease patients: a randomized controlled trial. Respir Res 2011;12:112.

24. Singh D, Agusti A, Anzueto A, et al. Global Strategy for the Diagnosis, Management, and Prevention of Chronic Obstructive Lung Disease: the GOLD science committee report 2019. Eur Respir J 2019;53:1900164.

25. Quanjer PH, Tammeling GJ, Cotes JE, et al. Lung volumes and forced ventilatory flows. Report Working Party Standardization of Lung Function Tests, European Community for Steel and Coal. Official Statement of the European Respiratory Society. Eur Respir J Suppl 1993;16:5-40.

26. Quanjer PH, Stanojevic S, Cole TJ, et al. Multi-ethnic reference values for spirometry for the 3-95-yr age range: the global lung function 2012 equations. Eur Respir J 2012;40:1324-43.

27. ATS Committee on Proficiency Standards for Clinical Pulmonary Function Laboratories. ATS statement: guidelines for the six-minute walk test. Am J Respir Crit Care Med 2002;166:111-7.

28. Jones PW, Tabberer M, Chen WH. Creating scenarios of the impact of COPD and their relationship to COPD Assessment Test (CAT ${ }^{\mathrm{TM}}$ ) scores. BMC Pulm Med 2011;11:42.

29. Launois C, Barbe C, Bertin E, et al. The modified Medical Research Council scale for the assessment of dyspnea in daily living in obesity: a pilot study. BMC Pulm Med 2012;12:61.

30. de Sá RB, Pessoa MF, Cavalcanti AGL, et al. Immediate effects of respiratory muscle stretching on chest wall kinematics and electromyography in COPD patients. Respir Physiol Neurobiol 2017;242:1-7.

31. Jeong M, Kang HK, Song P, et al. Hand grip strength in patients with chronic obstructive pulmonary disease. Int J Chron Obstruct Pulmon Dis 2017;12:2385-90.

32. Cote CG, Celli BR. Pulmonary rehabilitation and the BODE index in COPD. Eur Respir J 2005;26:630-6.

33. Varga J. Mechanism to dyspnoea and dynamic hyperinflation related exercise intolerance in COPD. Acta Physiol Hung 2015;102:163-75.

34. Varga JT, Szilasi M. Textbook of pulmonary rehabilitation. Spring Med Kiadó, Budapest, 2018.

35. Spruit MA, Singh SJ, Garvey C, et al. An official American Thoracic Society/European Respiratory Society statement: 
key concepts and advances in pulmonary rehabilitation. Am J Respir Crit Care Med 2013;188:e13-e64.

36. Li W, Pu Y, Meng A, et al. Effectiveness of pulmonary rehabilitation in elderly patients with COPD: A systematic review and meta-analysis of randomized controlled trials. Int J Nurs Pract 2019;25:e12745.

37. Puhan MA, Gimeno-Santos E, Cates CJ, et al. Pulmonary rehabilitation following exacerbations of chronic obstructive pulmonary disease. Cochrane Database Syst Rev 2016;12:CD005305.

38. Gloeckl R, Halle M, Kenn K. Interval versus continuous training in lung transplant candidates: arandomized trial. J Heart Lung Transplant 2012;31:934-41.

39. Shin KC. Physical activity in chronic obstructive pulmonary disease: clinical impact and risk factors. Korean J Intern Med 2018;33:75-7.

40. Waschki B, Kirsten A, Holz O, et al. Physical activity is the strongest predictor of all-cause mortality in patients with COPD: a prospective cohort study. Chest 2011;140:331-42.

41. Valkó L, Baglyas S, Tamáska E, et al. Use of noninvasive ventilation in critically ill patients. Orv Hetil 2018;159:1831-7.

42. Khilnani GC, Saikia N, Banga A, et al. Non-invasive ventilation for acute exacerbation of COPD with very high $\mathrm{PaCO}(2)$ : A randomized controlled trial. Lung India 2010;27:125-30.

43. Beckerman M, Magadle R, Weiner M, et al. The effects of 1 year of specific inspiratory muscle training in patients with COPD. Chest 2005;128:3177-82.

44. Spruit MA, Burtin C, De Boever P, et al. COPD and exercise: does it make a difference? Breathe (Sheff) 2016;12:e38-e49.

45. Knaut C, Mesquita CB, Caram LM, et al. Assessment of Aerobic Exercise Adverse Effects during COPD Exacerbation Hospitalization. Can Respir J 2017;2017:5937908.

46. Lee AL, Holland AE. Time to adapt exercise training regimens in pulmonary rehabilitation--a review of the literature. Int J Chron Obstruct Pulmon Dis 2014;9:1275-88.

47. Varga J. Porszasz J, Boda K, et al. Exploring the effect of high intensity continuous and interval training and at-home training respectively on rehabilitation of COPD patients. Med Thor 2008;61:135-43.

48. Jones RL, Noble PB, Elliot JG, et al. Airway remodelling in COPD: It's not asthma! Respirology 2016;21:1347-56.
49. Vagvolgyi A, Rozgonyi Z, Kerti M, et al. Effectiveness of pulmonary rehabilitation and correlations in between functional parameters, extent of thoracic surgery and severity of post-operative complications: randomized clinical trial. J Thorac Dis 2018;10:3519-31.

50. Vagvolgyi A, Rozgonyi Z, Kerti M, et al. Effectiveness of perioperative pulmonary rehabilitation in thoracic surgery. J Thorac Dis 2017;9:1584-91.

51. Kerti M, Balogh Z, Kelemen K, et al. The relationship between exercise capacity and different functional markers in pulmonary rehabilitation for COPD. Int J Chron Obstruct Pulmon Dis 2018;13:717-24.

52. Menadue C, Piper AJ, van't Hul AJ, et al. Non-invasive ventilation during exercise training for people with chronic obstructive pulmonary disease. Cochrane Database Syst Rev 2014;5:CD007714.

53. Hui KP, Hewitt AB. A simple pulmonary rehabilitation program improves health outcomes and reduces hospital utilization in patients with COPD. Chest 2003;124:94-7.

54. Paz-Díaz H, Montes de Oca M, López JM, et al. Pulmonary rehabilitation improves depression, anxiety, dyspnea and health status in patients with COPD. Am J Phys Med Rehabil 2007;86:30-6.

55. Spencer LM, Alison JA, McKeough ZJ. Maintaining benefits following pulmonary rehabilitation: a randomised controlled trial. Eur Respir J 2010;35:571-7.

56. Joyner MJ, Casey DP. Regulation of increased blood flow (hyperemia) to muscles during exercise: a hierarchy of competing physiological needs. Physiol Rev 2015;95:549-601.

57. Summermatter S, Santos G, Pérez-Schindler J, et al. Skeletal muscle PGC-1 $\alpha$ controls whole-body lactate homeostasis through estrogen-related receptor $\alpha$-dependent activation of LDH B and repression of $\mathrm{LDH}$ A. Proc Natl Acad Sci U S A 2013;110:8738-43.

58. Szucs B, Petrekanits M, Varga J. Effectiveness of a 4-week rehabilitation program on endothelial function, blood vessel elasticity in patients with chronic obstructive pulmonary disease. J Thorac Dis 2018;10:6482-90.

Cite this article as: Fekete $M$, Kerti M, Fazekas-Pongor V, Balazs P, Csizmadia Z, Nemeth AN, Tarantini S, Varga JT. Effect of interval training with non-invasive ventilation in severe chronic obstructive pulmonary disease-a prospective cohort study with matched control group. Ann Palliat Med 2021;10(5):5289-5298. doi: 10.21037/apm-21-378 